\title{
A STUDY OF THE ELASTIC BEHAVIOUR PRESENTED BY DIFERENT TYPES OF SEDIMENTARY ROCKS
}

Ana Paula Castro (UFF/ Petrobras), Eliane da Costa Alves (UFF), Guilherme Vasquez (Petrobras)

Copyright 2014, SBGf - Sociedade Brasileira de Geofísica

Este texto foi preparado para a apresentação no VI Simpósio Brasileiro de Geofísica, Porto Alegre, 14 a 16 de outubro de 2014. Seu conteúdo foi revisado pelo Comitê Técnico do VI SimBGt, mas não necessariamente representa a opinião da SBGf ou de seus associados. É proibida a reprodução total ou parcial deste material para propósitos comerciais sem prévia autorização da SBGt.

\section{INTRODUCTION}

Studies related to the elastic behavior of rocks have followed a growing trend in the last decades, given the importance of these researches to the understanding and interpretation of seismic and well log data. Currently, the seismic reflection method is the most widely used technique to petroleum exploration and field development and, therefore, it becomes a fundamental tool to oil industry. In this sense, the establishment of relations between the rocks' physical properties and their seismic signatures, from laboratory measurements is determinant to the enhancement of the seismic method capabilities, allowing the accomplishment of quantitative interpretation.

Several practical applications of rock physics can be quoted to sustain the relevance of the study of these properties, such as: sonic log quality control and calibration through critical comparison of lab data and log data; estimative of the seismic wave velocities in saturated rocks with different fluids (important to simulate the seismic response and to the construction of exploratory scenarios as well as feasibility and interpretation of seismic time lapse data sets); and the verification of the pressure dependence of the seismic properties, once in situ there are effective stress variation to which the rocks are put though during reservoir depletion (Dillon \& Vasquez, 2001; Morschbacher et al., 2010).

The scope of this paper is to study the elastic properties of different types of sedimentary rocks in laboratory and establish the relations between these properties (more specifically, the compressional and shear-wave velocities) with pressure variation and with the type of lithology. Throughout the measurement of wave velocity in some of the samples saturated with water, it was possible, also, to verify the validity of Gassmann model to these rocks, even at ultrasonic frequencies.

\section{STUDIED SAMPLES}

To accomplish this work, it has been used 15 samples of Paleozoic sedimentary rocks from outcrops of the Middle-West region in the United States, being those, 5 samples of Berea sandstone, 5 samples of Indiana limestone and 5 samples of Silurian dolomite. Table 1 provides the information on sample identification, the type of rock, the age and their formation.
Table 1 - Information about the samples Source: Archilla et al., 2012; isgs.illinois, ebeltz.net and US Geological Survey

\begin{tabular}{|c|c|c|c|c|}
\hline Rock & \begin{tabular}{c|} 
Samples \\
(Identification)
\end{tabular} & Formation & Origin & Age \\
\hline $\begin{array}{l}\text { Berea } \\
\text { Sandstones }\end{array}$ & $\begin{array}{l}\text { BRS001 } \\
\text { BRS002 } \\
\text { BRS003 } \\
\text { BRS016 } \\
\text { BRS017 }\end{array}$ & Bedford & $\begin{array}{l}\text { Ohio, } \\
\text { EUA }\end{array}$ & $\begin{array}{c}\text { Between } \\
\text { Mississippian } \\
\text { and Upper } \\
\text { Devonian }\end{array}$ \\
\hline $\begin{array}{c}\text { Indiana } \\
\text { Limestone }\end{array}$ & $\begin{array}{l}\text { IL011 } \\
\text { IL012 } \\
\text { IL013 } \\
\text { IL016 } \\
\text { IL017 }\end{array}$ & Salem & $\begin{array}{l}\text { Indiana, } \\
\text { EUA }\end{array}$ & $\begin{array}{c}\text { Middle } \\
\text { Mississippian } \\
\text { (335-340 Ma) }\end{array}$ \\
\hline $\begin{array}{l}\text { Silurian } \\
\text { Dolomite }\end{array}$ & $\begin{array}{l}\text { SD005 } \\
\text { SD006 } \\
\text { SD007 } \\
\text { SD010 } \\
\text { SD011 }\end{array}$ & Thornton & $\begin{array}{l}\text { Illinois, } \\
\text { EUA }\end{array}$ & $\begin{array}{l}\text { Silurian- } \\
\text { Devonian }\end{array}$ \\
\hline
\end{tabular}

\section{METHODOLOGY}

The tests to determine the rocks' elastic properties were made in the Laboratório de Física de Rochas from CENPES. The wave velocity measurement system allows the measurement o compressional, $\mathrm{P}\left(\mathrm{V}_{\mathrm{P}}\right)$, and shear-waves, $S\left(V_{S 1}\right.$ and $\left.V_{S 2}\right)$, and consist of an electronic part and a hydraulic part. The electronic part is composed by an oscilloscope and a pulse generator and the hydraulic part is composed of a hydraulic pump and a hydraulic vessel (recipient equipped with measurement metallic caps which connect to the electronic part of the system), according to Figure 1.

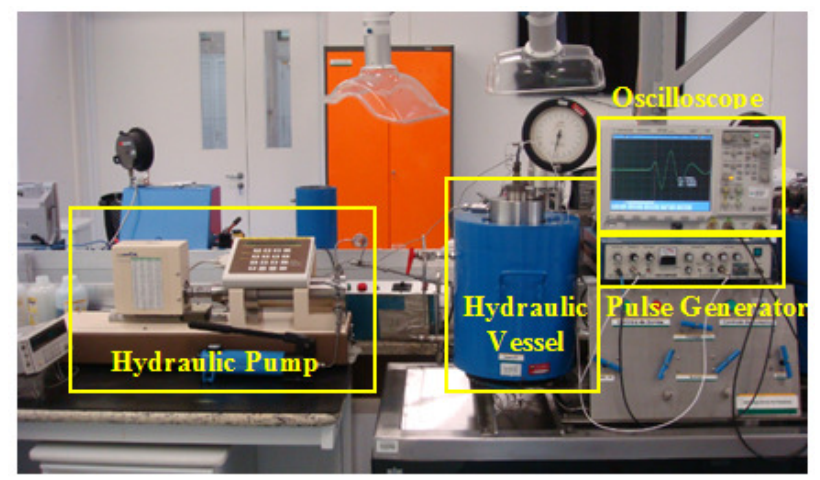

Figure 1 - Photograph of the electric wave speed propagation measurement system.

Inside the caps there are three piezoelectric transducers of ceramic material to the emission and reception of the electrical signal, according to the illustration on Figure 2. 


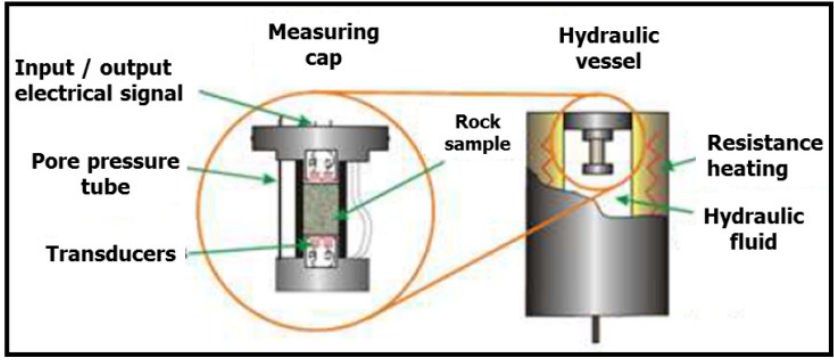

Figure 2 - Illustration on the hydraulic part of the elastic speed measure system in rock samples. Source: Laboratório de Física de Rochas from Cenpes

The electronic part is composed by a pulse generator and a power amplifier which provides a well-known electric signal to the piezoelectric transducers of ceramic material located in the caps of the hydraulic part. The transducers transform the electronic signal into a mechanical vibration, compressive or shear waves, according to the operator's choice and viceversa. The sample is, then, placed into the cell (measure head) and between the sample and the transducers it is placed a coupling material to distribute uniformly the acoustic waves all over the sample. After traveling through the rock sample, the mechanic vibration is received by another transducer, which converts it into an electric signal. This signal is amplified and after that, analyzed on the oscilloscope. The recorded waveforms in the oscilloscope are stored in a computer to further analysis.

The three cylindrical transducers that are built on each cap, generate, separately, a compressional wave $\left(V_{P}\right)$ and two shear waves orthogonally polarized $\left(\mathrm{V}_{\mathrm{S} 1}\right.$ and $\mathrm{V}_{\mathrm{S} 2}$ ). The velocities are determined measuring the transit time of the high frequency elastic pulse transmitted through the sample. The signal visualization in the oscilloscope indicates the transit time of the wave throughout the system with the sample. The elastic wave propagation velocity on the rocks is calculated dividing the sample length $(\Delta x)$ by the time $(\Delta t)$ effectively spent by the wave on the sample:

$$
V=\frac{\Delta x}{\Delta t}
$$

It is important to observe that the time effectively spent by the wave on the sample $(\Delta t)$ is equal to the time observed in the oscilloscope minus the system time or the delay time $t_{0}\left(\Delta t=t-t_{o}\right)$, where $t_{0}$ is the time spent by the signal in the electronic part and on the metallic caps when there is no sample inserted in the system, which means, it is the intrinsic system delay time.

The most traditional method the estimate the transit time is the picking of a determined event, as the first break or the maximum of the first peak. In the literature, the transit time estimative is done by the reading of the time of the first break, which means, the time of the first oscillatory energy that crosses the sample is the most commonly used method. However, not always the first break is an easy event to identify due to the presence of noise or other interferences in the signal, especially in heterogeneous samples. That is why, in this paper, the transit time estimative was done using as reference, the time of the first peak after the first break to wave $P$ and the time of the first valley after the first break to wave S. Considering the uncertainties associated to time and length measure, the error in these velocity measurements is of the order of $1 \%$ to $2 \%$ (Morschbacher et al., 2010).

\section{RESULTS AND DISCUSSIONS}

\subsection{Results from the measurement of P WAVE, S1 WAVE AND $S 2$ WAVE VELOCITIES}

The wave transit time was measured increasing the pressure in 500 psi steps until it reaches 5000 psi and with a posterior decrease of pressure from 5000 psi down to 500 psi, also done in 500 psi steps. Then, the velocity propagation of the compressional and shear waves was calculated using the Equation 1.

From the transit time data acquired and with the support of Matlab program, it was possible to represent the wave forms obtained on the samples in study, in a similar way of a seismogram. Figure 3 illustrates an example to form of P-wave obtained on a Berea sandstone sample, particularly (BRS001). This procedure described to a BRS001 sample was made to every 15 sample, obtaining the $P$-wave velocities.

Based on the graphs obtained, it was possible to observe that, at lower pressures, the recorded signal amplitude diminishes and also the definition of the wave first arrival becomes less clear, especially for the shear waves. For this reason, the correlations made with $V_{P}$ and $V_{S}$ data refers to the highest applied pressure (5000 psi).

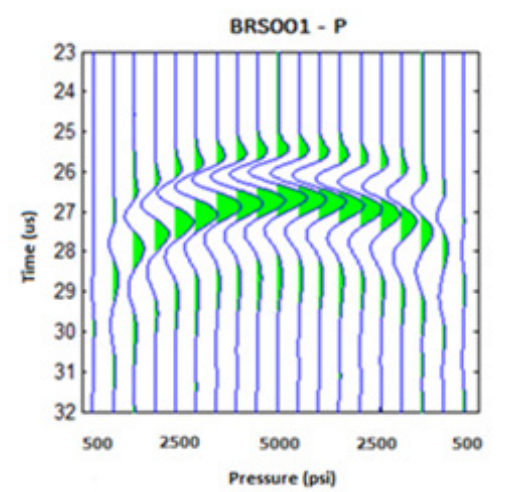

Figure 3 - Example of compressional wave recorded at different pressures for sample BRS001.

\subsection{Variation of elastic wave velocity with PRESSURE}

The compressional and shear-wave velocities increase with the increasing of the effective pressure, due to the closure of the micro cracks present on the rock. In sedimentary rocks, the velocities tend to asymptotic values at high applied pressures (Abreu, 2010). The tests made these characteristics evident. Figures 4 illustrates the trend of compressional and shear waves with the pressure variation, obtained on sample of each lithology. 

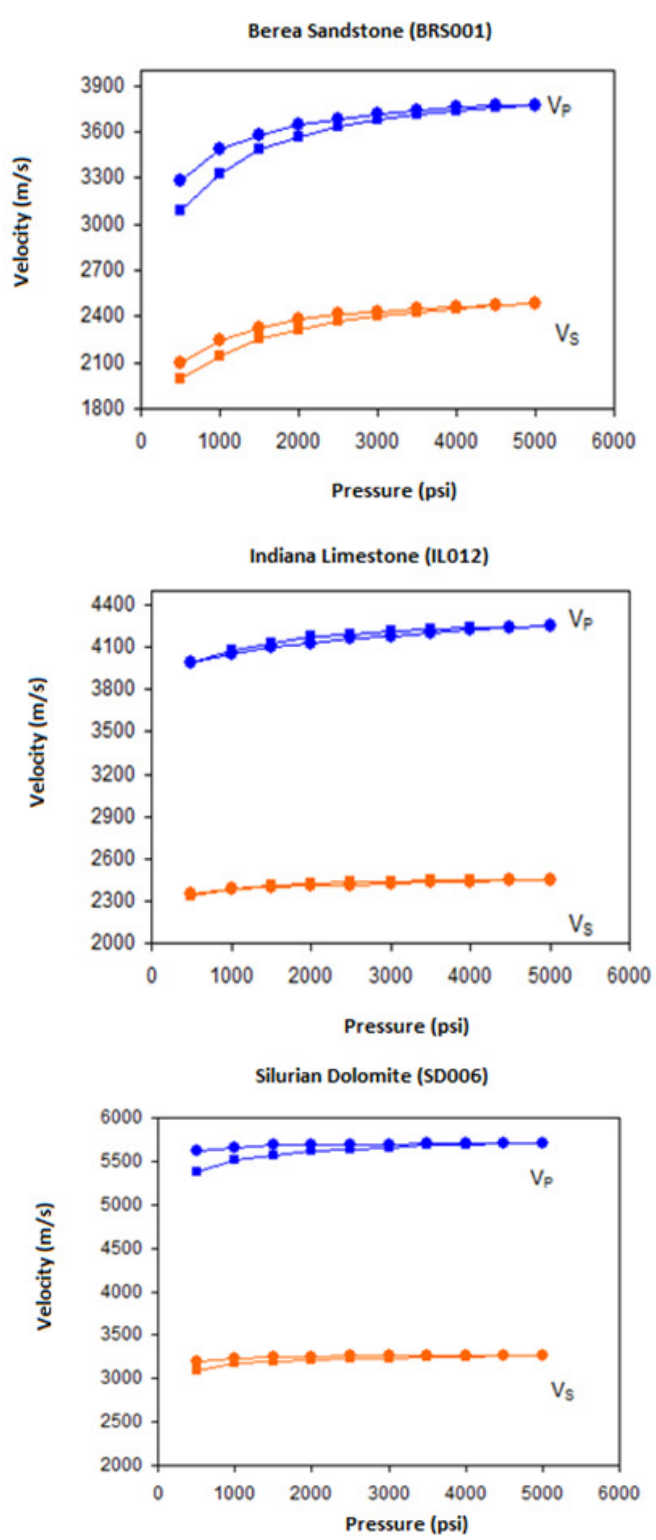

Figure 4 - The relation between the $P, S 1$ and S2-wave propagation velocities with pressure variation for one sample of each lithology.

For all the samples measured, it was observed similar trends. It is interesting noticing the phenomenon of hysteresis more evident in the sandstone, because when measuring the velocity with increasing pressure, it was obtained lower velocity values than the ones measured with the pressure decreasing to the same points. Which means, after the rock has been submitted to a pressure increase, the elastic properties behavior suffer a light alteration and with this, the $\mathrm{P}$-wave velocity at $3500 \mathrm{psi}$, for example, during the pressure increase is different from the obtained $\mathrm{P}$-wave velocity submitted at the same 3500 psi during the stress relief. In carbonates and dolomite rocks, the hysteresis phenomenon is observed in a lower intensity.

Although it has not happened a perfect coincidence of velocity values on the up going cycles, and in the stress relief cycles, the hysteresis effects can be considered as second order effect, generally, because it was not observed any marked variations in the results.

\subsection{ELASTIC WAVE PROPAGATION VELOCITY AND FLUID SUBSTITUTION}

One of the most relevant problems in the study of rock physics is the seismic velocity estimative in rocks saturated with different fluids, the so called fluid substitution problem (Mavko et al., 1998). This happens because the type of fluid (gas, oil or water) present in the pores influences the elastic properties of a rock in different ways. Usually, when a rock is under a compressive effect, there is an increase of pore pressure, to which it resists to the compression and, therefore, hardens the rock (Smith et al., 2003).

The fluid substitution technique most widely used is based on the Biot-Gassmann theory, because it allows the simulation of the elastic behavior of the rocks under different saturation conditions (Smith et al., 2003). Gasmann (1951, apud Abreu, 2010) proposed an equation to calculate the bulk modulus ( $K S A T$ ) of a saturated porous media from parameters known from the dry rock such as bulk modulus of the dry rock and of the solid matrix, the fluid and the porosity of the media. This way, the Gassmann theory foresees a resulting increase in the effective bulk modulus, KSAT, of a saturated rock throughout the following equation (Gassmann, 1951; apud Abreu, 2010):

$$
K_{S A T}=K_{D R Y}+\frac{\left(1-\frac{K_{D R Y}}{K_{G}}\right)^{2}}{\frac{\phi}{K_{F}}+\frac{(1-\phi)}{K_{G}}+\frac{K_{D R Y}}{K_{G}^{2}}}
$$

Where: $\quad K_{S A T}-$ saturated rock bulk modulus ; $K_{D R Y}-$ dry rock bulk modulus; $K_{F}-$ fluid bulk modulus or incompressibility; $K_{G}$ - solid matrix bulk modulus and $\phi$ - Porosity

The dry rock parameters necessary to calculate the saturated rock bulk modulus can be obtained by measuring the dry rock velocities in laboratory. Considering that the rock shear modulus does not change with saturation (Gassmann,1951), the wave velocities foreseen by Gassmann are given as:

$$
V_{P, S A T}=\sqrt{\frac{K_{S A T}+\frac{4}{3} \mu}{\rho_{S A T}}} \text { (3) and } V_{S, S A T}=\sqrt{\frac{\mu}{\rho_{S A T}}}
$$

In order to observe the influence of rock saturation in the compressional and shear wave propagation, three samples were saturated with water, one of each lithology, and then, it has been performed new $V_{P}$ and $V_{S}$ measurements. The chosen samples were BRS002, IL013 and SD006. Parallel, it has been performed also an estimative of $V p$ and $V s$ for the saturated rocks from the Gassmann equation (Eq. 2). To use this model, it has been adopted some values on the table of mineral bulk modulus Table 7) and for the water bulk modulus, it was considered a value of $2.25 \mathrm{GPa}$ (Mavko et al., 1998). 
Table 7- Average values of the elastic moduli and density to some sort of minerals

\begin{tabular}{|cccc|}
\hline Mineral & $\begin{array}{c}\text { Density } \\
\left(\mathrm{g} / \mathrm{cm}^{3}\right)\end{array}$ & $\begin{array}{c}\text { Bulk } \\
\text { Moduli } \\
(\mathrm{GPa})\end{array}$ & $\begin{array}{c}\text { Shear } \\
\text { Moduli } \\
(\mathrm{GPa})\end{array}$ \\
\hline Quartzo & 2.65 & 36.6 & 45 \\
Calcita & 2.71 & 76.8 & 32 \\
Dolomita & 2.87 & 94.9 & 45 \\
\hline
\end{tabular}

Figure 5 indicates the results obtained for $V_{P}$ and $V_{S}$ for dry and saturated rock, compared to the forecast made by the Gassmann model.
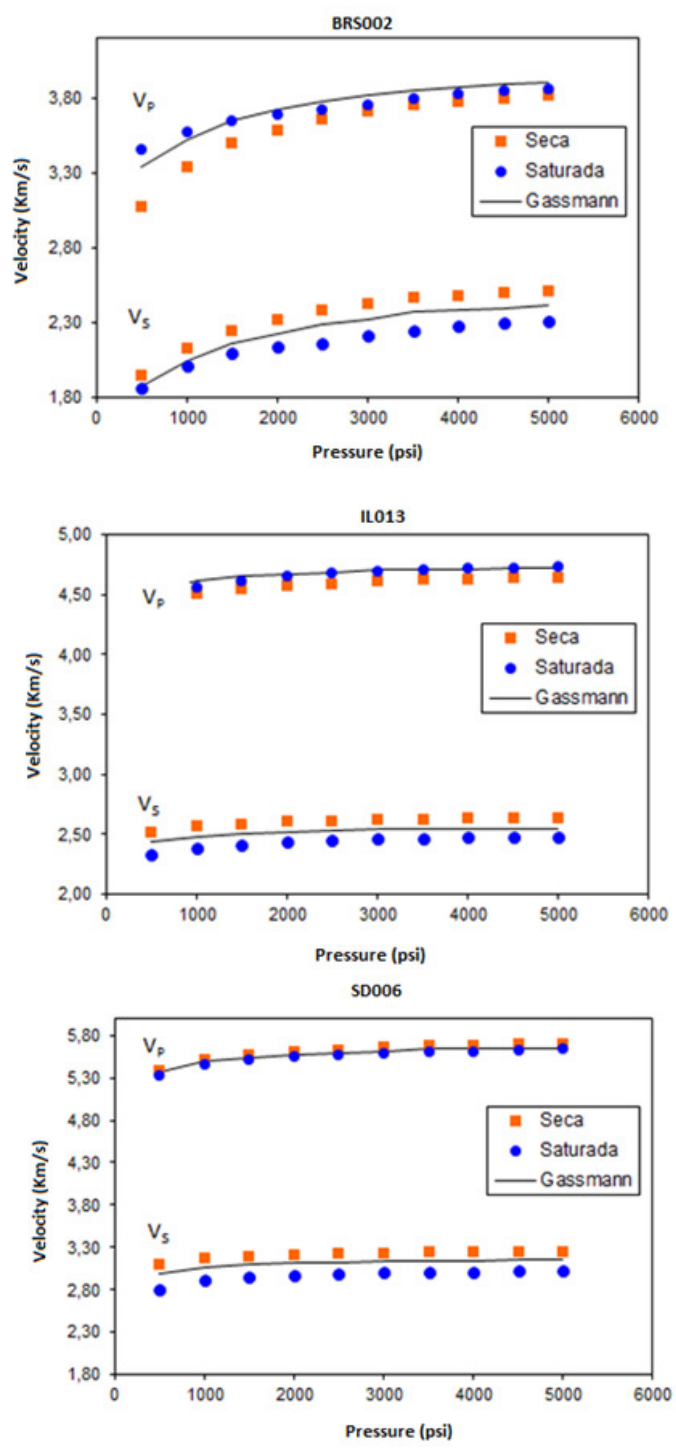

Figure 5 - Velocity of the samples BRS002, IL013 and SD006 dry and saturated with water, compared to Gassmann's forecast.

It was noted that the presence of fluids in the pore spaces affects the elastic properties of the rocks and, consequently, will affect its seismic signature. In the sandstone samples, which present more porosity, the effect is even greater. In a general way, the compressional velocity in rocks saturated with water is higher than the compressional velocity in dry rocks. To the shear-wave velocity, it is observed the contrary; the addiction of fluid reduces the shear-wave velocity, because the shear modulus remains (unchanged) unaltered while the density increases. The forecast to $P$ and S-wave velocity done with Gassmann's equations presented satisfactory results, with high precision data and errors lower than $3 \%$, even without respecting the theory assumption of low frequencies to accomplish the measurements (Gasmann,1951), once that in the laboratory, high frequencies are used. It is also interesting to point out that the Gassmann's model worked as well on the carbonate rocks as on the sandstone.

\section{CONCLUSION}

With these results, it was possible to study the correlations between the types of lithology and the of the elastic wave propagation velocity, and the influence of factors such as pressure and saturation presence of fluid in the elastic behavior of the rock.

It is evident that to determine the physical properties of the rocks from measurements done in a laboratory contributes to the establishment of relations between these properties and the seismic signature of the rock and, consequently, it has many important applications to the enhancement of the seismic method.

\section{ACKNOWLEDGMENTS}

The article authors thank all the staff of the Laboratório de Física de Rochas from Cenpes (Petrobras), specially the technicians Tagore Ostape, Guilherme Sollo and Marcos Leão for the support during the accomplishment of the tests and also thank the Geophysicist Márcio J. Morschbacher for the orientation and guidance over the result discussions.

\section{LITERATURE REFERENCES}

Abreu, ES, "Theoretical Modeling and Empirical Research Applied to the connection between the petrophysical properties and Elastic in carbonate rocks ", Master Thesis, UNICAMP, 2010.

Archilha, N., M. Supper; Misságia R., Neto, I.L. Comparison between the elastic constants and velocities estimated by the mineral composition of carbonate rocks. V Brazilian Symposium on Geophysics, November/2012 .

Dillon, LD, and Vasquez, GF ; Physics of rocks : fundamentals and applications ; Petrobras , 1st ed , 2000.

Gassmann , F. Elastic waves through a packing of spheres,Geophysics,16,pp.673-685,1951.

Mavko, G. , Mukerji , T. , Dvorkin , J., The Rock Physics Handbook : Tools for Seismic Analysis in Porous Media: Cambridge University Press, Cambridge , New York, USA,329pp.,1998.

Morschbacher , M. , Vasquez , G. , J. Justen " Methodology for Estimating the Seismic Speeds Testing Laboratory " , SimBGF IV ( Brazilian Symposium on Geophysics),November,2010.

Smith, T.M. , Sondergeldz , CH , Rai , CS Gassmann fluid substitutions : A tutorial. Geophysics, vol. 68, No. 2, p. 430-440, Março-Abril/2003. 